\title{
ANALISIS RESIDU BETA SIFLUTRIN \\ PADA TANAMAN KANGKUNG (Ipomoea reptans)
}

\author{
Ismarti \\ Dosen Prodi Pendidikan Matematika FKIP Universitas Riau Kepulauan Batam \\ Email: ismarti78@gmail.com
}

\begin{abstract}
ABSTRAK
Kesehatan individu tidak dapat dipisahkan dari kesehatan lingkungan. Pestisida yang diaplikasikan pada tanaman pangan dan sayuran dapat tertinggal pada tanaman, jatuh ke tanah dan menjadi sumber polutan di lingkungan. Dalam studi ini dilakukan analisis residu insektisida piretroid dengan bahan aktif beta siflutrin yang diaplikasikan pada tanaman kangkung. Insektisida yang digunakan adalah Buldock 25EC dengan dosis anjuran maksimum. Pengambilan residu beta siflutrin dilakukan dengan metode ekstraksi menggunakan pelarut diklorometana dan petroleum eter (1:1) dan proses clean up dengan kolom berlapis karbon dan florisil. Penetapan kadar dilakukan dengan kromatografi gas resolusi tinggi dengan detektor ECD (Electron Capture Detector).

Laju sorpsi pada tanaman kangkung lebih besar dari pada laju dissipasi mengindikasikan terjadinya akumulasi residu pestisida pada tanaman kangkung. Akumulasi beta siflutrin terjadi hingga hari ke-15 dan selanjutnya beta siflutrin mengalami dissipasi dengan konstanta laju 3,3 x $10^{-2}$ hari $^{-1}$. DT 50 beta siflutrin pada kangkung ditemukan cukup besar, yaitu 21,005 hari.
\end{abstract}

Kata kunci: residu beta siflutrin, Bulldock 2EC, kangkung

\section{PENDAHULUAN}

Penggunaan pestisida merupakan salah satu cara pengendalian orgenisme pengganggu tanaman (OPT) yang paling banyak digunakan oleh para petani, karena penggunaannya mudah dan hasilnya dapat dilihat dalam waktu yang singkat. Beta siflutrin merupakan salah satu insektisida piretroid sintetik yang banyak digunakan petani. Penggunaan insektisida sintesik merupakan dilema, disatu sisi sangat dibutuhkan untuk penyediaan pangan, namun di sisi lain berdampak negatif terhadap manusia, tumbuhan, hewan maupun lingkungan.

Praktek penggunaan pestisida oleh petani pada umumnya tidak didasarkan pertimbangan ekologi. Beberapa cara yang umum dilakukan oleh petani antara lain adalah penyemprotan pestisida dengan dosis tinggi, pencampuran berbagai jenis pestisida dan bahan lain, metode dan 
teknik penyemprotan yang belum atau tidak benar, frekuensi penyemprotan tinggi dan tidak memperhatikan waktu penyemprotan terakhir sebelum panen (Herawati dan Nadira, 2010).

Pestisida yang diaplikasikan tidak semuanya mengenai sasaran, kurang lebih hanya 20\% yang mengenai sasaran sedangkan $80 \%$ lainnya jatuh ke tanah. Akumulasi residu pestisida tersebut mengakibatkan pencemaran lahan pertanian. Apabila masuk ke dalam rantai makanan, sifat beracun bahan pestisida dapat menimbulkan berbagai penyakit.

Pestisida dapat meninggalkan residu pada tanaman yang dipanen. Residu yang terdapat pada sayuran sangat beresiko terhadap konsumen dan lingkungan sekitarnya. Kadar residu beta siflutrin yang melebihi batas maksimum residu pada buah, sayur dan sayuran hijau (MRL: 0,1$0,5 \mathrm{mg} / \mathrm{kg}$ ) berkaitan dengan kesehatan manusia. Penggunaan insektisida beta-siflutrin secara berlebihan membawa akibat buruk tidak hanya terhadap organisme pengganggu tanaman, tetapi juga organisme lain yang ada di sekitar, baik secara langsung atau tidak terkait dengan nasib insektisida beta-siflutrin setelah penyemprotan.

Persistensi beta-siflutrin pada iklim sub tropis telah dilaporkan pada berbagai komoditi sayuran seperti kubis, okra, tomat, sawi, sorgum, terung dan buncis (Saikia et al, 2005). Di Indonesia, penelitian tentang beta-siflutrin masih sangat terbatas. Persistensi beta-siflutrin telah diteliti pada tanaman kubis (Hidayat, 2008) dan lahan pertanian kubis (Asran, 2010). Penelitian ini bertujuan untuk menganalisis kadar residu beta-siflutrin pada tanaman kangkung dan mengetahui nilai konstanta laju sorpsi dan dissipasinya.

\section{TINJAUAN PUSTAKA}

Beta siflutrin adalah salah satu jenis insektisida piretroid sintetik yang merupakan satu stereoisomer dari siflutrin. Beta siflutrin dan siflutrin mempunyai sifat toksik yang sama, perbedaannya hanyalah keakutan toksiknya, dimana beta siflutrin lebih akut 2 sampai 5 kali dari siflutrin. Beta siflutrin berupa bubuk kristal tidak berwarna yang kelarutannya dalam air sangat rendah (hingga 0,002 $\mathrm{mg} / \mathrm{mL}$ ) tetapi relatif mudah larut dalam beberapa jenis pelarut organik.

Beta siflutrin adalah insektisida piretroid sintetik yang baik untuk racun kontak (mempunyai daya bunuh setelah tubuh hama terkena) dan racun lambung (mempunyai daya bunuh setelah hama memakan tanaman yang terkena pestisida). Beta siflutrin sangat toksik terhadap organisme perairan dan berbahaya bagi lebah tapi toksisitasnya rendah terhadap burung, mamalia dan cacing tanah (Maclachlan, 2007). 
Sifat fisikokimia pestisida penting dalam menentukan jalur dan laju degradasinya. Degradasi pestisida sangat dipengaruhi kondisi lingkungan, baik cahaya maupun mikroorganisme dengan jalan yang berbeda. Cahaya matahari secara signifikan berpengaruh terhadap fotodegradasi piretroid (Anonim, 1990). Namun dalam Mukherjee (2007) Nauman menyatakan bahwa beta siflutrin merupakan piretroid yang fotostabil.

Ukuran kuantitatif persistensi (keberadaan pestisida di lingkungan) adalah $\mathrm{DT}_{50}$ (Dissipation time $50 \%$ ). $\mathrm{DT}_{50}$ pestisida berbeda antara yang satu dengan yang lainnya tergantung sifat fisikokimia dan iklim wilayah penggunaannya. Namun, informasi tentang $\mathrm{DT}_{50}$ tidak mudah diperoleh karena tidak tercantum dalam label pestisida.

Hasil analisis residu dalam bahan pangan menurut MRLs FAO dalam kisaran $\mu \mathrm{g}-\mathrm{mg} / \mathrm{kg}$ (analisis kelumit) sehingga harus dipilih metode analisis yang sensitif. Teknik preparasi sampel untuk tingkat kelumit dapat di bagi menjadi tiga tahapan utama, yaitu ekstraksi, pemekatan, dan pembersihan (clean up) (Grob, 1995).

Ekstraksi merupakan langkah untuk memisahkan secara kuantitatif senyawa analit dari matriks pembawanya. Prosedur clean up digunakan untuk mengisolasi analit yang diharapkan dari ko-ekstraktan material sampel yang dapat mengganggu proses analisis. Penetapan kadar residu insektisida beta siflutrin dalam sampel menggunakan kromatografi gas dengan detektor penangkap elektron (ECD). Kromatografi merupakan metode pemisahan suatu senyawa dimana komponen-komponen yang akan dipisahkan didistribusikan antara 2 fase, salah satunya yang merupakan fase stasioner (diam), dan yang lainnya berupa fasa mobil (fasa gerak). Detektor ECD memiliki kepekaan yang tinggi dan selektif terhadap molekul senyawa yang mengandung halogen, karbonil terkonjugasi, nitro dan organo logam (Hendayana, 2006). Senyawa beta siflutrin mengandung halogen sehingga panggunaan detektor ECD diharapkan memiliki sensitivitas yang tinggi dalam proses penetapan kadar.

\section{HIPOTESIS}

Beta siflutrin tidak mudah mengalami volatilisasi dan cenderung terikat di permukaan tanaman (ditunjukkan oleh nilai konstanta Henry dan tekanan uap yang cukup rendah yaitu sebesar $3,2 \times 10^{-3}-1,3 \times 10^{-2} \mathrm{Pam}^{3} \mathrm{~mol}^{-1}$ untuk konstanta Henry dan $1,4 \times 10^{-8}-5 \times 10^{-8} \mathrm{~Pa}$ untuk tekanan uapnya) untuk memberi efek residual dalam jangka waktu lama. Daun dan batang kangkung memunyai lapisan lilin yang memungkinkan terjadinya interaksi antara lapisan lilin pada 
tanaman dengan beta siflutrin yang bersifat non polar. Apabila beta siflutrin disemprotkan pada tanaman yang mengandung lapisan lilin, maka beta siflutrin cenderung akan berinteraksi dengan lapisan lilin pada permukaan tanaman. Apabila beta siflutrin dengan sifat non polar dan lipofilik diaplikasikan pada tanaman kangkung, maka akan terjadi interaksi dengan lapisan lilin tanaman sehingga $\mathrm{DT}_{50}$ pada kangkung akan cukup besar.

\section{METODE PENELITIAN}

Sampel yang digunakan berasal dari tanaman kangkung darat yang diaplikasi dengan insektisida Bulldock 25 EC dengan dosis $1 \mathrm{ml} / \mathrm{l}$. Sampel kangkung diambil sebelum dan setelah aplikasi insektisida, pada hari ke 0, 7, 14, 16, 18, 20 dan 23 setelah tanam.

Sampel tanaman kangkung dipreparasi dengan aseton dan $\mathrm{Na}_{2} \mathrm{SO}_{4}$ anhidrat, lalu dilumatkan dengan maserator. Ekstraksi sampel kangkung dilakukan dengan menggunakan campuran petroleum eter dan diklorometana $(1: 1 \mathrm{v} / \mathrm{v})$.

Ekstrak yang diperoleh kemudian diuapkan untuk selanjutnya dilakukan proses clean up dengan kromatografi kolom dengan fase diam karbon-florisil (1:1 b/b) dan fase gerak diklorometan-toluen (1:1 v/v). Diharapkan dari proses yang dilakukan dapat diperoleh ekstrak sampel yang relatif bersih dari kontaminan yang mungkin akan menggangu dalam proses penetapan kadar.

Penetapan kadar residu insektisida beta siflutrin dalam sampel dilakukan dengan menggunakan kromatografi gas dengan detektor penangkap elektron (GC-ECD).

\section{HASIL DAN PEMBAHASAN}

\section{A. Sistem kromatografi gas, Waktu Retensi dan Stabilitas Instrumen}

Kondisi operasional kromatografi gas yang digunakan adalah:

a. Kolom: kolom kapiler dengan panjang $25 \mathrm{~m}$ dan diameter 0,25 mm.

b. Fase diam: $c p$ sil8 $c b$ (disesuaikan dengan beta siflutrin yang non polar)

c. Fase gerak: gas helium dengan laju alir $50 \mathrm{~mL} /$ menit pada tekanan $100 \mathrm{kPa}$.

d. Detektor: Electron Capture Detector (GC-ECD)

e. Temperatur:

- $\quad$ Temperatur injektor : $270^{\circ} \mathrm{C}$.

- Temperatur kolom: $150^{\circ} \mathrm{C}$ (1 menit), kenaikan $10^{\circ} \mathrm{C} /$ menit, $250^{\circ} \mathrm{C}$ (10 menit ) (kondisi temperatur terprogram) 
- Temperatur detektor : $290^{\circ} \mathrm{C}$.

Kromatogram beta siflutrin menunjukkan 2 puncak yang dihasilkan dari dua pasang diastereoisomer yang dominan kelimpahannya dalam campuran yaitu cis diastereomer II dan trans diastereomer IV ( gambar 1).

Waktu retensi senyawa beta siflutrin dari 3 kali penginjeksian adalah 19,097 $\pm 0,269$ menit untuk puncak pertama dan 19,497 $\pm 0,266$ menit untuk puncak kedua.

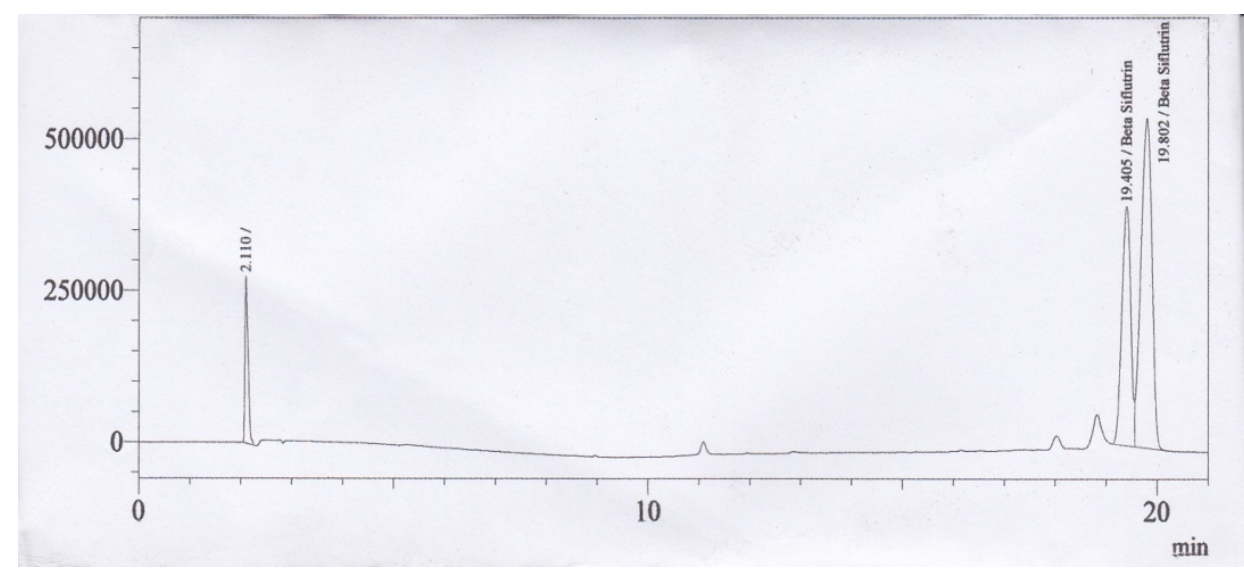

\section{Gambar 1. Kromatogram beta siflutrin yang diperoleh dari kondisi optimum GC- ECD dengan kolom kapiler, fase diam cpsil8cb dengan laju alir gas helium $50 \mathrm{~mL} / \mathrm{menit}$ pada tekanan $100 \mathrm{kPa}$}

Stabilitas instrumen ditentukan dari nilai waktu retensi yang dilakukan dengan 3 kali pengulangan. Waktu retensi senyawa beta siflutrin adalah 19,097 \pm 0,269 menit untuk puncak pertama dengan koefisien variansi $\mathrm{CV}_{1}$ sebesar $1,41 \%$, sedangkan waktu retensi untuk puncak kedua adalah 19,497 \pm 0,266 menit dengan $\mathrm{CV}_{2}$ sebesar 1,36\%. Nilai koefisien variansi yang diperoleh $<5 \%$ menunjukkan kestabilan kondisi optimum instrumen yang digunakan pada penelitian ini.

\section{B. Analisis Residu Beta Siflutrin pada Tanaman Kangkung Darat}

Residu pestisida dalam tumbuhan dapat ditemukan akibat penyerapan melalui akar atau lewat daun dan batang pada saat penyemprotan. Rambut akar memainkan peranan penting dalam penyerapan pestisida melalui tanah. Pengambilan pestisida melalui akar dimulai dengan absorpsi dan selanjutnya translokasi melalui rambut akar. 


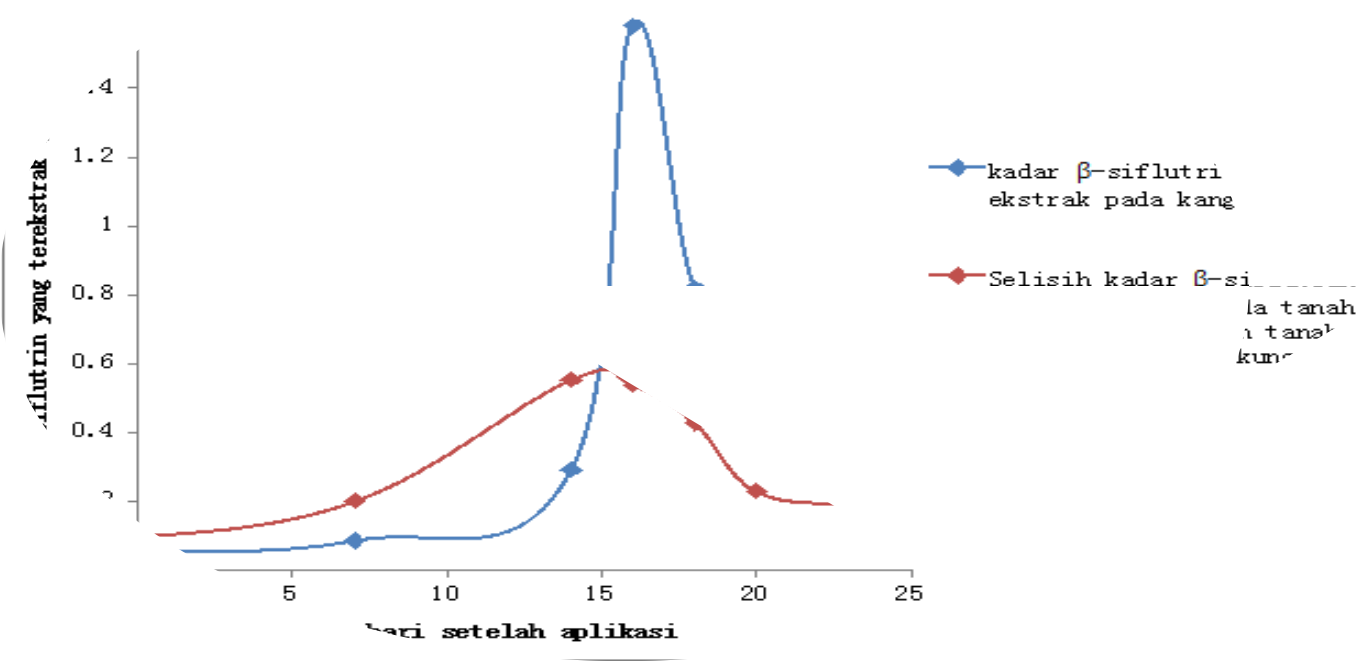

Gambar 2. Kurva kadar beta-siflutrin yang terekstrak pada kangkung dan selisih kadar beta-siflutrin pada tanah tanpa kangkung dan tanah yang ditanami kangkung

Gambar 2 menunjukkan profil kadar beta-siflutrin yang terekstrak pada kangkung. Pada

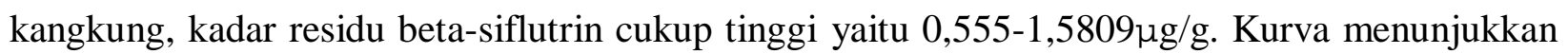
peningkatan residu beta-siflutrin yang terekstrak pada tanaman kangkung mengindikasikan adanya akumulasi residu beta-siflutrin pada kangkung. Dari Tabel 1 juga dapat dilihat bahwa laju sorpsi beta-siflutrin pada kangkung jauh lebih besar dari pada laju dissipasinya. Akumulasi residu beta-siflutrin pada kangkung terjadi hingga hari ke-16 dan selanjutnya beta-siflutrin mengalami dissipasi dengan konstanta laju 3,3 x 10 $0^{-2}$ hari $^{-1}$.

Beta-siflutrin tidak mudah mengalami volatilisasi dan cenderung terikat di permukaan tanaman (ditunjukkan oleh nilai konstanta Henry dan tekanan uap yang cukup rendah yaitu sebesar $3,2 \times 10^{-3}-1,3 \times 10^{-2} \mathrm{~Pa} \mathrm{~m}^{3} \mathrm{~mol}^{-1}$ untuk konstanta Henry dan $1,4 \times 10^{-8}-5 \times 10^{-8} \mathrm{~Pa}$ untuk tekanan uapnya) untuk memberi efek residual dalam jangka waktu lama. Daun dan batang tanaman memunyai lapisan lilin yang memungkinkan terjadinya interaksi antara lapisan lilin pada tanaman dengan beta- siflutrin yang bersifat non polar.

Sorpsi pestisida pada tumbuhan melalui penyemprotan dimulai dengan penetrasi deposit melalui kutikula dan stomata diikuti dengan transport apoplastik, synplastik dan translokasi melalui floem. Surfaktan dapat menekan partisi pestisida ke membran kutikula dengan melarutkan membran tersebut ke dalam misel sehingga permeabilitas kutikula meningkat. Keberadaan surfaktan dapat meningkatkan ruang bebas yang tersedia untuk difusi pestisida 
Surfaktan juga dapat mempertinggi kelarutan bahan kimia sehingga mempengaruhi partisi pestisida ke dalam akar dan fase akuos di luar akar. (Katagi, 2008).

Kangkung termasuk tumbuhan hidrofit yang beradaptasi dengan lingkungan yang memiliki ketersediaan air melimpah dan kelembapan tinggi. Pada umumnya tumbuhan hidrofit memiliki kutikula yang sangat tipis bahkan beberapa tumbuhan tidak memiliki kutikula sama sekali. Epidermis yang dimiliki hanya selapis. Sel-sel epidermis ini memiliki dinding yang tipis dan mempunyai banyak stomata. Pada tumbuhan hidrofit, stomata lebih banyak terdapat pada permukaan daun (Mulyani, 2006). Hal ini memungkinkan beta-siflutrin lebih mudah berdifusi ke dalam jaringan tanaman kangkung.

Dari Tabel 1 juga teramati bahwa $\mathrm{DT}_{50}$ pada tanah yang ditanami kangkung lebih kecil daripada $\mathrm{DT}_{50}$ pada tanah tanpa kangkung, mengindikasikan berkurangnya residu beta-siflutrin dalam tanah yang ditanami kangkung. Fenomena ini dapat dihubungkan dengan pengambilan beta-siflutrin dari dalam tanah melalui akar tanaman untuk kemudian ditranslokasikan ke bagian tanaman.

$\mathrm{DT}_{50}$ beta-siflutrin pada kangkung cukup besar, yaitu 21,005 hari. Pada tanaman kangkung, degradasi mikrobial dapat diabaikan. Dissipasi terjadi hanya melalui jalur degradasi kimia.

\section{KESIMPULAN}

Berdasarkan hasil penelitian yang telah dilakukan maka dapat disimpulkan bahwa:

1. Kadar residu beta siflutrin pada tanaman kangkung meningkat dengan lamanya waktu aplikasi dengan kisaran konsentrasi 0,0555-1,2859 ppm dengan kadar tertinggi dicapai pada hari ke-16 sesudah penyemprotan.

2. Laju sorpsi dan dissipasi beta siflutrin mengikuti kinetika orde pertama dengan konstanta

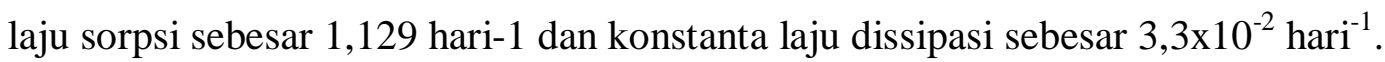

\section{DAFTAR PUSTAKA}

Anonim, 1990, Deltamethrin: Environmental Health Criteria 97, United Nation Environmental Programme, International Labour Organization, and the World Health Organization, Geneva.

Asran, 2010, Peranan Bahan Organik Tanah dan Adjuvan Polioksietilen Alkil Aril Eter terhadap Disipasi Residu Beta Siflutrin pada Lahan Pertanian Kubis (Brassica Oleraceae), Tesis, Fakultas Farmasi, Universitas Gajah Mada, Yogyakarta 
Grob, L. R., 1995, Modern Practice of Gas Chromatography, p 291-295, John Wiley and Sons Inc, New York.

Hendayana, S., 2006, Kimia Pemisahan. Penerbit Remaja Rosdakarya, Bandung.

Herawati dan Nadira, A., Kajian Penggunaan Pestisida oleh Petani Pemakai serta Informasi dari Berbagai Stakeholder Terkait di Kabupaten Karo Sumatera Utara, http://www.info.stppmedan.ac.id diakses September 2010

Hidayat, Danie, 2008, Pengaruh Adjuvant Polioksietilen Alkil Aril Eter terhadap Dinamika Beta Siflutrin pada Kubis (Brassica Oleracea), Tesis, Fakultas Farmasi, Universitas Gajah Mada, Yogyakarta

Katagi, T., 2008, Surfactant Effect on Environmental Behavior of Pesticides, Reviews of Environmental Contamination and Toxicology, Springer, 71-174

Maclachlan, Dugald, 2007, Cyfluthrin/Beta-Cyfluthrin , Australian Quarantine And Ispection Service, Canberra, pp.121-150

Mukherjee, I., M.Gopal and D.S. Mathur, 2007, Behavior of $\beta$-Cyfluthrin After Foliar Application on Chickpea (cicer aretinium L) and Pigeon pea (cajanus cajan L.) , Bull Environ Contam Toxicol, 78, 85-89

Mulyani, S., 2010, Anatomi Tumbuhan, edisi ke-5, Kanisius, Yogyakarta 